\title{
FACILITATING CRITICAL ENQUIRY ABOUT RACE AND RACISM IN A DIGITAL ENVIRONMENT: DESIGN CONSIDERATIONS
}

\author{
S. I. Brokensha* \\ e-mail: broksha@ufs.ac.za \\ T. Conradie* \\ e-mail: conradiems@ufs.ac.za \\ *Department of English \\ University of the Free State \\ Bloemfontein, South Africa
}

\section{ABSTRACT}

Increasingly, instructors working in higher education settings are exploiting asynchronous online forums to facilitate difficult dialogues on social issues such as sexuality, race, and diversity. We interrogate the task design we employed to construct a digital space in which undergraduate English Studies students could discuss race and racism in the context of a study of contemporary understandings and manifestations of race. Within the realm of computer-mediated discourse analysis, we employed Booth and Hultén's (2003) taxonomy of key contributions to meaningful online discussion to determine if students' posts displayed not only knowledge-sharing discourse, but also knowledge-construction and knowledge-creation discourses. We discovered that although students co-constructed knowledge and, in some instances, created new artefacts, they mainly shared and compared ideas. We therefore consider how our task design should be altered to foster critical enquiry. Although not our main focus, we also take into account phenomena our data analysis revealed that cannot be overlooked when it comes to online discussions of contentious issues. These phenomena include emotional responses to racism and microaggressions. We adopt the view that these elements are an unavoidable part of a difficult dialogue, and that facilitators need to prepare their students to converse in uncomfortable spaces.

Keywords: asynchronous online forums, difficult dialogues, task design, knowledge sharing, knowledge construction, knowledge creation

\section{INTRODUCTION}

At higher education settings in South Africa, virtual learning environments have become popular and appear to be productive spaces in which to conduct emotionally fraught dialogues on social justice issues such as racism, gender inequality or religious intolerance (cf. Buchanan, Wilson and Gopal 2008, 671). Asynchronous online discussion forums in particular have been hailed, not only as spaces in which students can critically explore difficult issues (Licona and 
Guring 2011, 3), but also as constituting a significant equaliser (Murphy and Fortner 2014, 338 ), with Bender $(2003,9)$ going so far as to claim that the nature of these forums reduces race-based inequities among students. Following Dare (2011, 280), we do not ascribe to this colour-blind ideology; it is an unavoidable fact that discussions of race and racism - whether carried out in a face-to-face environment or in an online space - may generate microaggressions, covert 'everyday exchanges that send denigrating messages to certain individuals because of their group membership’ (Sue 2010, xvi). Pre-eminent scholar, Crain Soudien (2010, 893) observes that in the face of legal injunctions against overt racism, such micro-aggressions have become one of the most prevalent manifestations of contemporary racism, and a noteworthy obstacle to transformation that should be of equal interest to critical scholars alongside broader structural matters. Part of the challenge that Soudien $(2010,894)$ engages with, is the re-current denial that racism continues to affect tertiary institutions, which raises further obstacles to its exposure and discussion. With regards to online interaction, Dare (2011, 280, 283) adds the caveat that the notion of 'an online [...] post-race utopia' perpetuates the view that virtual spaces must offer students a comfortable, agreeable learning experience. Discomfort should not be regarded as an inappropriate or negative emotion, but as a resource that students can harness when it comes to critical enquiry of diversity (cf. Reidel and Salinas 2011, 13). We will return to the topic of discomfort later on. Suffice it to say, we are of the opinion that the use of asynchronous online discussion forums may foster critical engagement in the context of a dialogue on race and racism, on condition that task design is sound.

Our main objective is to report on a computer-mediated discourse analysis of an asynchronous online discussion (AOD) we set up in 2014 for our third-year English students, who were engaged in studies of post-colonial literature and sociolonguitic analyses of a variety of discourse settings. In the context of a study of contemporary understandings and manifestations of race, students were asked to respond to a September 2013 feature article in Cosmopolitan entitled 'Your parents are racist. What about you?' During the discussions, they were required to assess the usefulness of the advice about racism offered by the writer and to determine if the advice was relevant to South Africa as well as to the university at which they were registered. We were interested in exploring whether or not our task design (i.e., the curriculum, the given learning objectives, discussion guidelines, and assessment procedures) helped stimulate high levels of critical engagement about race and racism during the discussions. We define such engagement as that in which students' patterns of interaction transcend straightforward knowledge-sharing discourse about race and racism to reflect knowledge-construction and knowledge-creation discourses too. The fundamental distinction 
between the last two kinds of discourse is that the former kind, mediated by social interactions, involves students tapping into their existing knowledge and experience to re-structure that knowledge and develop deeper insights into given concepts, while the latter results in the creation and improvement of new artefacts such as perspectives, theories and models (Van Aalst 2009, 261-262). Encouraging the production of all three discourses facilitates learning around social justice topics because a student's experiences and knowledge are integrated with the experiences and knowledge of fellow students, potentially leading to what Guthrie and McCracken $(2010,1)$ refer to as 'intellectually transformative’ interactions.

Before sketching the background to the study and then reporting on the results and implications of our study for task design, we take a closer look at what the literature tells us about AODs, particularly as it relates to facilitating difficult dialogues on social matters.

\section{ASYNCHRONOUS ONLINE DISCUSSION FORUMS}

With the increasing use of blended-learning platforms in higher-education settings worlwide, not to mention the growing number of student enrollments, educators have begun to recognise the instructional benefits of AODs. When it comes to potentially sensitive or controversial discussions of racism, sexuality, or power and privilege, to name a few, one of the most significant strengths of AODs centres around students being able to generate authentic dialogue around such topics (Hadjionnou 2007, 371). Studies indicate that authenticity is achieved in AODs through interactions that (1) reflect higher-order processes such as asking questions or disagreeing with statements made; (2) generate sophisticated knowledge rather than simply objectify it (Journell 2008, 320; cf. Hadjionou 2007, 371); (3) do not follow a pre-determined script (Journell 2008, 320); and (4) avoid heavy reliance on instructor intervention. Indeed, as far as the latter element is concerned, a study by An, Shin and $\operatorname{Lim}(2009,758)$ suggests that (over-)intervention by instructors can inhibit insightful thoughts and opinions because students may feel obliged to address the majority of their comments to them. Other studies indicate that instructor presence in the online environment may result in domination of the discussion by the instructor (Redmond 2011, 1055).

Another advantage of AODs, and of particular interest to us, is that they may promote higher-order thinking skills, but only if certain variables are taken into account. For instance, in a recent exploration of critical engagement in online learning, Lee $(2014,41,49)$ concluded that contrary to popular belief, cognitive presence alone does not guarantee higher levels of knowledge construction; students may be so intent on cognitive functions that their contributions amount to serial monologues. Lee $(2014,49)$ argues that higher social presence 
density appears to improve levels of critical engagement because it is through collaboration that knowledge is co-constructed and meaning negotiated (cf. Cui, Lockee and Meng 2013, 668; Remesal and Colomina 2013, 357; Smith and Flaherty 2013, 15). Indeed, much of the literature on AODs and knowledge construction focuses on a social constructivist pedagogy (Zingaro and Oztok 2012, 71; Thomas 2013, 199), which is based on Vygotsky's (1978) theories of cognitive development. Nevertheless, findings remain contradictory, with some researchers asserting that social presence is either a superficial add-on or that it does not have a significant impact on cognitive engagement (Shea, Hayes, Vickers, Gozza-Cohen, Uzuner, Mehta, Valchova and Rangan 2010, 17; Annand 2011, 40). Proponents of cognitive constructivism base their beliefs on Piaget's (1977) theory of cognitive development, arguing that knowledge is constructed in individuals and not through active collaboration with others.

Since the 1990s, a number of analysts working in the realm of qualitative research have attempted to devise content analysis coding schemes for meaningful online discussion that reflect either a social or cognitive constructivist perspective. According to Lucas, Gunawardena and Moreira $(2014,575)$, these models constitute an improvement on early studies of the quality of asynchronous communication which focused almost exclusively on quantitative data, measuring, amongst other things, the number of messages posted by a particular student or the number of posts generated in a given conversational thread (cf. Yang, Richardson, French and Lehman 2011, 44). The first researcher to develop a model of content analysis was Henri (1992), who evaluated the cognitive processes involved in computer-mediated conferencing (CMC). Although several researchers have subsequently employed Henri's (1992) Cognitive Framework (Chang, Lin and Tsai 2012; Nandi, Hamilton, Chang and Balbo 2012), one of the framework's major flaws is that since it was devised with teacher-directed instruction in mind, it disregarded the co-construction of knowledge in groups. Gunawardena, Lowe and Anderson (1997) endeavoured to overcome this flaw by proposing the Interaction Analysis Model, which identified five levels of social knowledge construction, namely, (i) the sharing of ideas/claims; (ii) the discovery and probing of inconsistent information; (iii) the co-construction of knowledge; (iv) the testing and revision of this knowledge; and (v) the application of newlyconstructed meaning. While this model addresses student-student as well as student-instructor interaction, it does not take interaction between students and content into account (Yang et al. 2011, 46). A third influential model is Garrison, Anderson and Archer's (2001) Community of Inquiry model, which considers cognitive, social, and teaching presence in argumentation/critical thinking and which Guthrie and McCracken (2010, 3) therefore suggest is an appropriate model for discussing social justice issues online because the three elements 
are regarded as core constructs in critical enquiry (Ke 2010, 818; cf. Thomas 2013, 199). One weakness of the model is that studies that employ it tend to measure perceived student satisfaction rather than learning (Rourke and Kanuka 2009, 20, 22). Another criticism is that the framework does not explicitly describe what students need to do in order to establish and maintain critical enquiry (Xin 2012, 5).

Although these frequently cited instruments have specific shortcomings, they have been shaped by prior knowledge (Paulus and Phipps 2008, 462) and so should not simply be discarded. What is more, 'applying existing instruments fosters replicability and the validity of the instrument ...' (De Wever, Schellens, Valcke and Van Keer 2006, 11). This is particularly important when one considers that there are more than 50 coding schemes in existence to understand and characterise AODs (Weltzer-Ward 2011, 56; 2014, 77).

What makes it fairly difficult to select a particular content analysis model is that each has a different perspective on what constitutes a meaningful online discussion. We contend that it is important to take cognitive processes (Henri 1992), argumentation (Garrison et al. 2001), and social knowledge construction (Gunawardena et al. 1997) into consideration when attempting to foster critical enquiry among students (cf. Gao, Wang and Sun 2009, 69): Working within a sub-type of content analysis referred to as computer-mediated discourse analysis (Herring 2010, 238), we adopt and expand on a coding instrument devised by Paulus and Phipps (2008) which takes all three perspectives into account.

\section{CODING INSTRUMENT}

Paulus and Phipps' (2008) coding scheme (Table 1) is based on Booth and Hultén’s (2003) taxonomy of essential (but not sufficient) contributions to meaningful online discussion. Factual contributions, which in our view correspond to knowledge-sharing discourse, are those that students employ when they make and expand on statements, ideas, or thoughts, and ask or answer straightforward, information-driven questions, for example. Reflective contributions mirror knowledge-construction discourse, and entail students agreeing or disagreeing with one another, challenging specific ideas, responding to rebuttals, interpreting one another's claims, and asking probing questions. Learning contributions are consistent with knowledge-creation discourse, since they involve students synthesising knowledge from two or more conversational threads to create new artefacts, sometimes seeing them from a unique perspective. Booth and Hultén’s (2003) framework also comprises a fourth dimension - participatory contributions, which help students establish their presence and acknowledge that of their peers. Speech acts typically associated with these contributions are naming, greeting, and joking. We believe that 
it is important to include participatory contributions to compensate for the absence of social context cues in AODs (cf. Shen and Chen 2014, 180).

Like Paulus and Phipps (2008, 465), our unit of analysis is 'one [functional] move in an ongoing conversation that serves a particular function in the discourse'. Of course, a move can reflect more than one function. Thus, for instance, 'I agree with Tibi' reflects a name (a participatory contribution) as well as an agree (a reflective contribution).

Table 1: Essential contributions to productive online discussion (adapted from Paulus and Phipps 2008, 482-483 and Booth and Hultén 2003, 79-81)

\begin{tabular}{|c|c|c|c|}
\hline Contribution & Move & Description & Dataset example \\
\hline \multirow[t]{11}{*}{ Participatory } & Name & Addresses a peer by name & 'Sipho' \\
\hline & Greet & Greets a peer & 'Hi guys' \\
\hline & Apologise & Makes an apology & 'Sorry for only coming back to you now!' \\
\hline & Suggest & Makes a suggestion & $\begin{array}{l}\text { 'you can use practical [examples] to } \\
\text { elaborate' }\end{array}$ \\
\hline & Invite & Extends an invitation & $\begin{array}{l}\text { 'Do you want to meet for coffee } \\
\text { sometime?' }\end{array}$ \\
\hline & Mitigate & Softens a comment & $\begin{array}{l}\text { 'Please take that as a rhetorical question } \\
\text { if you wish not to answer it' }\end{array}$ \\
\hline & Joke & Makes a humorous comment & $\begin{array}{l}\text { 'My Lady' (After South Africans began } \\
\text { following the Oscar Pistorius trial, people } \\
\text { began addressing each as 'My lady' after } \\
\text { learning that this is the appropriate title for } \\
\text { female judges.) }\end{array}$ \\
\hline & Acknowledge & $\begin{array}{l}\text { Acknowledges a participant } \\
\text { through a positive statement }\end{array}$ & 'Thanks' \\
\hline & Encourage & $\begin{array}{l}\text { Encourages a participant } \\
\text { through a positive statement }\end{array}$ & 'Keep it up girl' \\
\hline & $\begin{array}{l}\text { Transition/ } \\
\text { Temporal }\end{array}$ & $\begin{array}{l}\text { Signals the start of a new topic } \\
\text { or guides the discussion to a } \\
\text { previous topic }\end{array}$ & $\begin{array}{l}\text { 'However, as mentioned in some other } \\
\text { post earlier ...' }\end{array}$ \\
\hline & Close & Concludes the conversation & :) \\
\hline \multirow{8}{*}{$\begin{array}{l}\text { Factual } \\
\text { (Knowledge } \\
\text { sharing) } \\
\text { Social } \\
\text { knowledge } \\
\text { construction: } \\
\text { sharing/ } \\
\text { comparing ideas }\end{array}$} & Ask 1 & $\begin{array}{l}\text { Asks a question not directed at } \\
\text { a specific participant }\end{array}$ & $\begin{array}{l}\text { 'However, has anyone ever taken the } \\
\text { time to analyze the behaviour of } \\
\text { children?' }\end{array}$ \\
\hline & Ask 2 & $\begin{array}{l}\text { Asks a question of a specific } \\
\text { participant }\end{array}$ & 'What do you think?' \\
\hline & Answer 1 & $\begin{array}{l}\text { Participant answers his or her } \\
\text { question }\end{array}$ & $\begin{array}{l}\text { 'does that then mean it makes you a } \\
\text { racist as well? } \\
\rightarrow \text { No it does not' }\end{array}$ \\
\hline & Answer 2 & $\begin{array}{l}\text { Participant answers a peer's } \\
\text { question }\end{array}$ & 'I would say it is relevant, yes' \\
\hline & Claim/Idea & $\begin{array}{l}\text { Reflects a claim/idea that is } \\
\text { not explicitly related to another } \\
\text { participant's post }\end{array}$ & $\begin{array}{l}\text { 'The problem I have is that people } \\
\text { generally tend to throw the word racism } \\
\text { around' }\end{array}$ \\
\hline & Re-state & Repeats a claim made & 'The advice I think is constructive' \\
\hline & Extend 1 & $\begin{array}{l}\text { Expands on a claim based on } \\
\text { personal experience or } \\
\text { general knowledge }\end{array}$ & $\begin{array}{l}\text { 'An example of this would be "all Africans } \\
\text { can dance well" or "all Asian women are } \\
\text { submissive and therefore don't like to } \\
\text { fight", as opposed to someone who is } \\
\text { physically different' }\end{array}$ \\
\hline & Extend 2 & $\begin{array}{l}\text { Expands on a claim by } \\
\text { referring to a theory/learning } \\
\text { materials/lecture notes }\end{array}$ & $\begin{array}{l}\text { 'In psychology, "contact hypothesis" } \\
\text { refers to the belief that regular interaction } \\
\text { between members of different groups } \\
\text { reduces prejudices' }\end{array}$ \\
\hline $\begin{array}{l}\text { Reflective } \\
\text { (Knowledge } \\
\text { construction) }\end{array}$ & Challenge & Challenges a peer's ideas & $\begin{array}{l}\text { 'I [don't] understand how you [can't] } \\
\text { believe in interracial marriages, can you } \\
\text { please elaborate?' }\end{array}$ \\
\hline
\end{tabular}




\begin{tabular}{|c|c|c|c|}
\hline Contribution & Move & Description & Dataset example \\
\hline \multirow{7}{*}{$\begin{array}{l}\text { Argumentation: } \\
\text { critiquing ideas } \\
\text { Cognitive } \\
\text { processing: } \\
\text { interpreting } \\
\text { ideas and } \\
\text { asking probing } \\
\text { questions }\end{array}$} & $\begin{array}{l}\text { Respond to } \\
\text { challenge }\end{array}$ & $\begin{array}{l}\text { Responds to a peer's } \\
\text { challenge }\end{array}$ & $\begin{array}{l}\text { 'I think that yes some of the things our } \\
\text { parents say stick in our brains, but there } \\
\text { is still a choice we have to make to use } \\
\text { those comments or not' }\end{array}$ \\
\hline & Interpret & $\begin{array}{l}\text { Attempts to understand a } \\
\text { peer's claim }\end{array}$ & $\begin{array}{l}\text { 'From what I gather, you are of the } \\
\text { opinion that racism is taught to us either } \\
\text { by our parents, the society or the } \\
\text { community at large' }\end{array}$ \\
\hline & Ask 3 & $\begin{array}{l}\text { Asks a question that goes } \\
\text { beyond mere clarification } \\
\text { (associated with a challenge) }\end{array}$ & $\begin{array}{l}\text { 'I [don't] understand how you [can't] } \\
\text { believe in interracial marriages, } \\
\rightarrow \text { can you please elaborate?' }\end{array}$ \\
\hline & Agree 1 & $\begin{array}{l}\text { Participant agrees with } \\
\text { another participant's post but } \\
\text { does not expand on his/her } \\
\text { agreement }\end{array}$ & 'I agree with what you are saying' \\
\hline & Agree 2 & $\begin{array}{l}\text { Participant disagrees with a } \\
\text { student's contribution, but } \\
\text { does not explain why }\end{array}$ & $\begin{array}{l}\text { 'Yes, the thing is, we are not forced to } \\
\text { conform to any standard nowadays! In a } \\
\text { country where freedom is inevitable, we } \\
\text { make our own choices based on our } \\
\text { moral values' }\end{array}$ \\
\hline & Disagree 1 & $\begin{array}{l}\text { Participant disagrees with } \\
\text { another peer's post and does } \\
\text { not explain why }\end{array}$ & $\begin{array}{l}\text { 'I disagree with you [...] that racism } \\
\text { should be forgotten' }\end{array}$ \\
\hline & Disagree 2 & $\begin{array}{l}\text { Participant disagrees with } \\
\text { another peer's post and } \\
\text { explains why }\end{array}$ & $\begin{array}{l}\text { 'I would have to disagree with you, racism } \\
\text { is not taught but rather people adopt the } \\
\text { constructs of racism and practice them } \\
\text { (by being racist)' }\end{array}$ \\
\hline $\begin{array}{l}\text { Learning } \\
\text { (Knowledge } \\
\text { creation) } \\
\text { Improved } \\
\text { understanding: } \\
\text { synthesising } \\
\text { knowledge and } \\
\text { generating news } \\
\text { idea }\end{array}$ & Learn & $\begin{array}{l}\text { Participant identifies a new } \\
\text { idea or reflects on the idea } \\
\text { from a new angle on the basis } \\
\text { of at least two conversational } \\
\text { threads }\end{array}$ & 'I did not even think of that approach' \\
\hline
\end{tabular}

\section{TASK DESIGN, ASSUMPTIONS AND RESEARCH QUESTIONS}

As noted in the introduction, our third-year English students, whose curriculum covered postcolonial literature and sociolinguistics, were asked to read a magazine article entitled 'Your parents are racist. What about you?' and then to discuss this article in an asynchronous online forum. In addition to being asked to discuss why they believed the information in the article to be relevant or irrelevant to their own tertiary institution, students were provided with 'Tips for making an online discussion personally useful'. These tips were quite explicit, requesting, for example, that students ask pertinent questions, challenge one another, make substantive claims, and refine or revise their opinions. Discussions took place over a three-week period, after students had spent the first three weeks of the semester exploring language and power, language and gender as well as political discourse within a critical discourse-analytical (CDA) framework. (This exploration continued over the rest of the semester which totalled 14 weeks.) The prescribed textbook for studying the various constructs was Simpson and Mayr's (2010) Language and power: A resource book for students (Routledge). Additional materials 
comprised research articles with a focus on gender ideologies (del-Teso-Craviotto 2006), male heterosexuality (Attwood 2005), as well as race and racism (DeCuir and Dixson 2004; Verwey and Quayle 2012). Students were not assigned to specific discussion board groups, but were allowed to initiate conversational threads and contribute to threads of their choice. They were awarded only an attendance mark which made up five percent of the total number of marks for the module. The discussions had a scaffolding purpose, since they were aimed at preparing students to achieve the main learning outcome of the sociolinguistics component of the course, which was to carry out two CDA-based analyses of specific discourse settings.

Our assumption that students' interactions would reflect critical engagement was based in part on the premise that our detailed discussion prompts, which emerged from our conceptual framework summarised in Table 1, would elicit not only knowledge-sharing discourse, but also knowledge-construction and knowledge-creation discourses. Two years previously, students had completed a mandatory course for all first-years during which they were encouraged to debate diverse social issues via AODs, and so we surmised that they would be relatively competent in argumentative dialogue. Moreover, students had already explored a variety of texts on the social construction of race in their previous two years of study, and so we postulated that, in addition to interacting with one another, they would also engage with our course content during discussions. Given our student-centred approach to teaching and learning, and based on previous research suggesting that instructor intervention may hinder student-student interaction (Boyd 2102, 198; cf. Lin, Hong and Lawrenz 2012, 379), we allowed students to initiate and maintain the discussions without our mediation.

To test our assumptions, we asked ourselves the following question: Do students' contributions to the online discussion transcend knowledge sharing to include knowledgeconstruction and knowledge-creation discourses? Next, we asked, If levels of knowledge construction and knowledge creation are low, why is this the case and what do we need to do to remedy this?

\section{METHODOLOGY}

We made use of purposive sampling (cf. Flick 2014, 175) with a view to determining what kinds of contributions our students generated over a three-week period. We logged 129 students' 438 contributions to Blackboard's discussion forum and ultimately coded a total of 2359 functional moves. Student demographics are illustrated in Table 2 below. The archived data are available for perusal in hard-copy format, although students' names and student numbers have been erased, while the electronic log generated on Blackboard has been deleted 
so that students' comments and identities cannot be linked if a search is conducted. Any other information that can lead to identification (such as the use of a student's name by a fellow student) has also been removed.

Table 2: Student demographics

\begin{tabular}{|l|l|l|}
\hline Gender & Female & 100 \\
& Male & 29 \\
\hline Race & Asian & 1 \\
& Coloured & 11 \\
& Black & 50 \\
& White & 67 \\
\hline Home Language & isiNdebele & 1 \\
& isiZulu & 5 \\
& isiXhosa & 8 \\
& Sesotho & 18 \\
& Setswana & 9 \\
& Sepedi & 1 \\
& Tshivenda & 1 \\
& Xitsonga & 2 \\
& SiSwati & 1 \\
& English & 24 \\
& Afrikaans & 58 \\
& Korean & 1 \\
\hline Degree & BA Education & 92 \\
& BA Media Studies and Journalism & 18 \\
& BA Language Practice & 3 \\
& BA Language Studies & 3 \\
& BA Human Movement Sciences & 1 \\
& BA Human and Societal Dynamics & 1 \\
& Occasional Studies (Non-degree) & 1 \\
\hline
\end{tabular}

We imported the contributions we collected to NVivo 10 and created nodes for Paulus and Phipps' (2008, 482-483) coding scheme. We also either added or refined the existing categories based on an exhaustive analysis of our data (Table 1). Ultimately, we added a suggest under participatory contributions and an interpret and agree 3 under reflective contributions, since the coding scheme did not accommodate such moves. Under factual contributions, we refined an extend, distinguishing between two kinds. We made this distinction to determine whether students expanded on their claims based on personal experience/general knowledge or on course content. We also refined asks and answers so that we could ascertain whether or not students were addressing one another or the discussion topic itself. Finally, under reflective contributions we refined agrees and disagrees, since we were interested in finding out whether these moves were substantive or not.

Employing a software tool such as NVivo is beneficial for a number of reasons. In addition to assisting in the refinement of coding practices, it also allows researchers to synchronise their analyses (Williams and Lahman 2011, 149). We were able to code students' posts independently of each other and record our comments using NVivo's memo tool. This gave us 
the opportunity to compare our analyses and observations and reach consensus in the case of disagreements. In other words, besides examining the data individually, we could also analyse it collaboratively, thus achieving trustworthiness (Ertmer, Sadaf and Ertmer 2011, 165). A third colleague in the field of linguistics cross-validated 50 percent of our data analysis. Our observations about the data, a sample of which is provided in Figure 1, were dense and meticulous, which allows for 'thick description' (Geertz 1973, 26-27). This kind of description does not only allow researchers to immerse themselves in the data, thus avoiding the so-called ‘tactile-digital divide’ (Gilbert 2002, 216), but also affords greater transparency because researchers can share insights, challenges, and doubts (Tracy 2010, 842). Another advantage of NVivo's memo is that it constitutes an audit trail of the analysis process. An audit trail is particularly vital in qualitative research settings which are marked by subjectivity and researcher bias (Petty, Thomson and Stew 2012, 381), the latter being a weaknesses of purposive sampling.

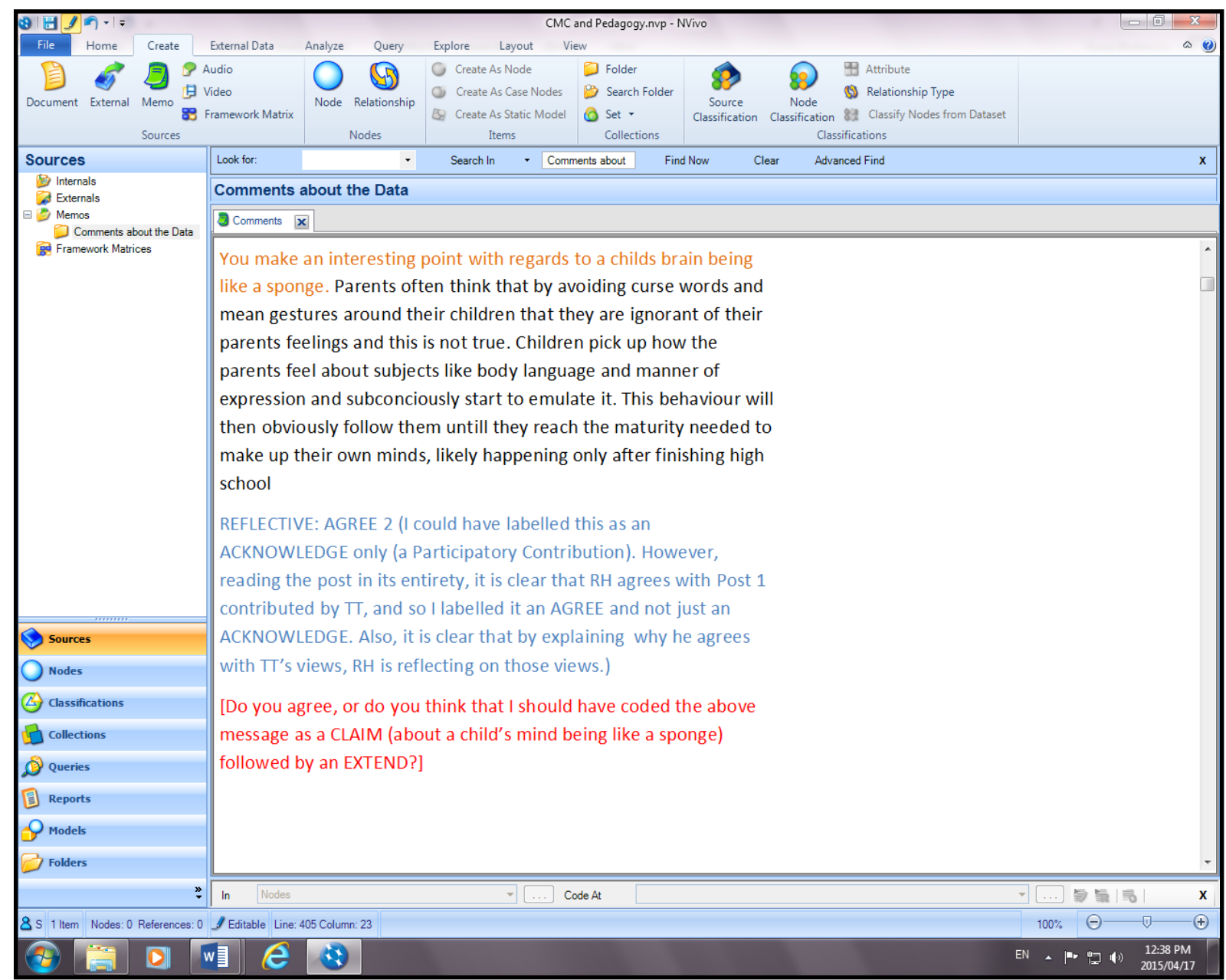

Figure 1: An example of thick description using NVivo's memo tool 


\section{FINDINGS}

Do students' contributions to the online discussion transcend knowledge sharing to include knowledge-construction and knowledge-creation discourses?

We were able to determine that, to varying degrees, students generated all of the functional moves reflected in Booth and Hultén's (2003) taxonomy (Table 3). There were only 376 participatory contributions, which is not an unexpected finding, since researchers report that these contributions are far more prevalent in synchronous CMC than in asynchronous environments (cf. Giesbers, Rienties, Tempelaar and Gijselaers 2014, 32). Most contributions - 1554 in total - were factual in nature, with the vast majority of these contributions constituting claims, which means that students' posts reflected knowledge sharing rather than knowledge construction and knowledge creation. When it came to elaborating on claims, students relied heavily on personal experience or general knowledge; claims bolstered by reference to course content were infrequent. Most questions were not directed at specific classmates, and the few that were directed at individuals were not necessarily answered: 22 specific questions were posed, but only ten of these received answers. Reflective contributions comprised only 17 per cent of the total number of moves. Most of the moves in this category were agree 2s, which is a positive finding, since it signals that students at least provided reasons for agreeing with one another. Although there were very few disagrees, it was encouraging to find that most of these were substantiated. What was disappointing is that there were very few challenges and responses to challenges. What was positive is that where challenges occurred, probing questions were asked. Very few messages were learning contributions: a mere 20 reflected seeing ideas from a novel perspective.

Table 3: Findings

\begin{tabular}{|l|l|l|}
\hline Contribution & Move & Number \\
\hline Participatory & Name & 142 \\
\cline { 2 - 3 } & Greet & 24 \\
\cline { 2 - 3 } & Apologise & 2 \\
\cline { 2 - 3 } & Suggest & 1 \\
\cline { 2 - 3 } & Invite & 3 \\
\cline { 2 - 3 } & Mitigate & 7 \\
\cline { 2 - 3 } & Joke & 1 \\
\cline { 2 - 3 } & Acknowledge & 111 \\
\cline { 2 - 3 } & Encourage & 1 \\
\cline { 2 - 3 } & Transition/Temporal & 73 \\
\cline { 2 - 3 } & Close & 11 \\
\cline { 2 - 3 } & Total number of participatory moves & $\mathbf{3 7 6}$ (16\% of the total) \\
\hline Factual & Ask 1 & 143 \\
\cline { 2 - 3 } & Ask 2 & 36 \\
\cline { 2 - 3 } & Answer 1 & 22 \\
\cline { 2 - 3 } & Answer 2 & 10 \\
\cline { 2 - 3 } & Claim/ldea & 797 \\
\hline
\end{tabular}




\begin{tabular}{|l|l|l|}
\hline Contribution & Move & Number \\
\hline \multirow{5}{*}{ Reflective } & Re-state & 18 \\
\cline { 2 - 3 } & Extend 1 & 506 \\
\cline { 2 - 3 } & Extend 2 & 22 \\
\cline { 2 - 3 } & Total number of factual moves & $\mathbf{1 5 5 4}$ (66\% of the total) \\
\hline & Challenge & 32 \\
\cline { 2 - 3 } & Respond to Challenge & 21 \\
\cline { 2 - 3 } & Interpret & 5 \\
\cline { 2 - 3 } & Ask 3 & 56 \\
\cline { 2 - 3 } & Agree 1 & 58 \\
\cline { 2 - 3 } & Agree 2 & 195 \\
\cline { 2 - 3 } & Disagree 1 & 2 \\
\cline { 2 - 3 } & Disagree 2 & 40 \\
\cline { 2 - 3 } & Total number of reflective moves & $\mathbf{4 0 9}(\mathbf{1 7 \%}$ of the total) \\
\hline \multirow{5}{*}{ Learning } & Learn & $\mathbf{2 0}$ \\
\cline { 2 - 3 } & Total number of learning moves & $\mathbf{2 0}(\mathbf{0 . 8 \%}$ of the total) \\
\hline & Total number of moves & $\mathbf{2 3 5 9}$ \\
\hline
\end{tabular}

\section{Additional findings}

Our focus was on identifying levels of critical engagement in students' discussions, but we could not overlook responses that expressed certain emotions or those that signalled subtle or overt forms of bias. We identified strong emotional statements such as 'I often feel ashamed because of all my privileges' and 'I feel ashamed of being white'. Bias was apparent in claims such as (1) 'I am not a racist at all, but I am sick and tired of having to deal with this issue', (2) 'Personally I feel that we are making this whole racism/Apartheid thing bigger than what it really is', and (3) '... now I'm forced to interact with other people from different races'. Soudien (2010) and Sue (2010) warn that such responses emerge from an already racialised consciousness, arguing that this denies and rejects the experiences and worldviews of others. More importantly, such responses can be challenged for failing to reflect on the way denial serves the interests of some groups over others by, for example, occluding present-day power dynamics. Leonardo and Porter (2010) contend that having to deal with this kind of rejection/denial raises unique barriers to making non-white voices heard, and risks unbalancing the dialogue in the favour of whiteness.

How did we identify statements as those in (1)-(3) as possibly constituting racism? In ground-breaking work in which they contended that interracial discourse almost inevitably reflects micro-aggressions, whether consciously or unconsciously generated, Sue, Capodilupo, Torino, Bucceri, Holder, Nadal and Esquilin (2007) developed a taxonomy of racial microaggressions, which we employed to identify our students' contributions as possibly constituting racism. Based on a review of the literature, Sue et al. $(2007,272)$ argue that the term racial micro-aggressions, which was first coined by Pierce (1970), 'best [describes] the phenomenon [of racism] in its everyday occurrence'. Sue and her colleagues distinguish among micro- 
assaults, micro-insults, and micro-invalidations, which manifest themselves on verbal, nonverbal or environmental levels. Micro-assaults are explicit and mainly violent racial put-downs intended to cause harm, while micro-insults are rude, insensitive communications that debase an individual's racial identity. Micro-invalidations are comments that reject the emotions, experiences and thoughts of an individual belonging to a specific racial/ethnic group. According to Sue (2010, 33), who further developed and refined the 2007 taxonomy, it is possible that a comment such as that encapsulated in (1) is a micro-invalidation because it signals a denial of the possibility of involuntary racism: it denies the value of the input and evaluations of the racialised other. Similarly, statement (2) statement reflects a micro-invalidation in the sense that it ' ... [nullifies] the psychological thoughts, feelings, or experiential reality of a person of [colour]' (Sue 2010, 33). The comment in (3) also constitutes a micro-invalidation: in the context of the conversational thread, it denies the need for institutionalised efforts towards transformation.

The significance of such responses and the pedagogical strategies that need to be taken into account to deal with them are discussed in the next section.

\section{DISCUSSION}

If levels of knowledge construction and knowledge creation are low, why is this the case and what do we need to do to remedy this?

A space of safety and discomfort: Freed from the potential risk of losing face in a brick-andmortar classroom, students may experience an asynchronous online environment as less threatening, potentially fostering more detailed and challenging discussion of controversial topics such as the one we selected. Leonardo and Porter $(2010,139)$ warn that maintaining safety should not constitute a goal in its own right, especially since it runs the risk of militating against detailed interaction on difficult topics. Striking a middle ground that, on the one hand, recognises the potentially threatening nature of such discussions, while concurrently encouraging an openness to risk and vulnerability is thus a perennial challenge of such education. The value reflected in the principles of a safe environment as espoused by Holley and Steiner (2005) cannot be denied. After all, students want to feel free to express themselves without fear of ridicule or attack (Arao and Clemens 2013, 138). Yet, 'authentic learning about social justice often requires the very qualities of risk, difficulty, and controversy that are denied as being incompatible with safety' (Arao and Clemens 2013, 139). Indeed, Arao and Clemens $(2013,136)$ argue that the notion of a safe space in the context of social justice and diversity needs to be re-conceptualised as a brave space instead. 
In online interactions, students' reduced sense of risk appear to stem, at least in part, from the reduced power relations reflected in online communication - what Martin $(2013,7)$ refers to as the 'toppling [of] the established social order', since they are no longer constrained by the rules governing face-to-face interaction. What is more, students feel more comfortable conducting a difficult dialogue in a so-called lean, text-based medium as opposed to a rich medium such as that reflected in face-to-face communication (Blau and Barak 2012, 15). While employing a non-threatening space is not debatable and can result in meaningful discussion, it can also be dysfunctional (Gayle, Cortez and Preiss 2013, 6) in the sense of inhibiting students from challenging their own and one another's biases (Mayo 2010, 521). In fact, it is necessary to 'prepare [...] students for feelings of discomfort' (Le Roux and Mdunge 2012, 82) in order to facilitate a difficult dialogue on race and racism. Emotion expressed as anger, alienation or hurt, for example, cannot be divorced from critical enquiry:

Positioning emotion as a resource that can help us understand diverse perspectives rather than as a problem can move us closer to deeper and more nuanced understanding of diverse perspectives. It also can help students and teachers move out of their comfort zones and begin the hard work of re-examining ideas, values and beliefs ... (Reidel and Salinas 2011, 8).

We did not explicitly sensitise our students to the kinds of discomfort they would experience in the context of an emotionally-laden discussion, although our discussion prompts included recommendations as to how students should respond to opposing points of view. Analysed in the context of specific discussion threads, comments such as '[I'm] so sick of people ... making everything about race'; 'I started to think about any offensive comment I've made'; and 'I experienced many incidents where racism was [perpetrated] in my presence' clearly point to our students' emotional responses to racism, ranging from resentment and defensiveness to guilt and pain. These comments underscore the need to assist students in coping with emotions triggered by social justice issues (cf. Cleveland-Innes and Campbell 2012, 273).

Before making some suggestions as to how to assist students in this regard, we deem it necessary to concede that we are well aware of the complexities involved in perceiving and interpreting emotions generated in a text-based CMC environment. One of the main criticisms of such an environment is that the absence of non-verbal cues and intonation precludes an understanding of emotion. However, several studies (Walther, Loh and Granka 2005; Hancock, Landrigan and Silver 2007; Gill, Gergle, French and Oberlander 2008) have shown that participants in a text-based environment are able to 'adapt their emotional expression and sensitivity to the verbal channels' (Hancock, Gee, Ciaccio and Lin 2008, 295) of this environment. Participants may, for instance express what they feel through emotion words 
(Quan and Ren 2010, 105) or through emotion symbols that include emoticons and punctuation (Cui, Zhang, Liu and Ma 2011, 238).

To return to helping students cope with negative affect, we intend to adopt the principles proposed by clinical psychologist Lydia Khuri, who has worked in the areas of social justice and multicultural education at tertiary level. Against the background of psychotherapy, Khuri (2004, 602) suggests that to reduce negative affect, facilitators should (1) build trust among students as well as between themselves and their students, and one step towards achieving this trust is to (2) initiate low-level discussions before moving on to high-risk ones (cf. Quaye 2012, 544). Khuri $(2004,602)$ recommends that students begin with an ice-breaker activity in which they learn about one another and share their concerns about discussing social justice issues in a non-judgemental environment. An effective strategy to foster trust is to ensure that students are aware of what is expected of them during discussions. In this regard, we were careful to provide students with course content as well as with detailed instructions on how to establish and maintain a meaningful discussion. Khuri $(2004,603)$ also advises instructors to (3) establish an attitude of empathy towards their students' subjective experiences, (4) monitor their own emotional reactions to the content of a discussion to avoid steering the dialogue in a specific direction, and (5) encourage students to integrate their intellectual and affective responses to one another's ideas. This last principle ‘enables participants to not merely intellectualize social disparities and injustices, but to develop the ability to connect affectively with their peers ...' (Khuri 2004, 545).

Interestingly enough, although we did not explicitly draw students' attention to the inevitability of the conversational space carrying a certain degree of emotional risk, their moves in a number of instances signalled their sensitivity to one another's feelings (Table 4): by acknowledging one another's views in a positive manner, apologising for a time delay, mitigating their disagreements/challenges, extending an invitation, or attempting to interpret comments or viewpoints accurately so as to avoid causing offence, some students displayed a considerate attitude towards one another, which in turn indicates an attempt to connect with their peers on a personal rather than intellectual level. Are affective phenomena such as these significant in any way? To paraphrase Khuri's (2004, 607-608) answer to this question, affective engagement is not incidental to productive discussion. This claim is echoed by Cleveland-Innes and Campbell $(2012,285)$, who go so far as to argue that emotional engagement is a fundamental part of learning in an online environment. Indeed, a recent study by Mega, Ronconi and De Beni $(2014,121)$ suggests that emotion may have a positive impact on a student's motivation, academic achievement, and self-regulation. At this stage, however, 
it is best to be cautious; very few studies exist that have explored how emotion may affect online learning (Marchand and Gutierrez 2012, 150). To compound matters, in their review of more than 100 studies, Rienties and Rivers $(2014,1)$ found that while emotions could influence learners' behaviour and cognition in a positive way in blended or online settings, they could also have a negative or neutral impact.

Table 4: Affective phenomena reflected in students' moves

\begin{tabular}{|c|c|c|}
\hline Contribution & Move & Example \\
\hline Participatory & Acknowledge & 'I really value your opinion' \\
\hline Participatory & Apology & 'Sorry for only coming back to you now!' \\
\hline Participatory & Invite & 'PS Do you want to meet for coffee sometime?' \\
\hline Participatory & Mitigate & $\begin{array}{l}\text { "Although you mentioned you have black friends do you think at times you } \\
\text { have "habitual behaviours or thoughts" that can be considered racist (as } \\
\text { mentioned in the article)? } \\
\rightarrow \text { Please take that as a rhetorical question if you wish not to answer it' }\end{array}$ \\
\hline Participatory & $\begin{array}{l}\text { Mitigate } \\
\text { Apology }\end{array}$ & $\begin{array}{l}\rightarrow \text { 'I hope I have not misinterpreted any of what you have written } \\
\rightarrow \text { or even offended you' }\end{array}$ \\
\hline Reflective & Interpret & $\begin{array}{l}\text { 'I thought about it some more and realised that you might have meant that } \\
\text { it is unfair for people to just focus on racism in terms of colour' }\end{array}$ \\
\hline Reflective & Interpret & $\begin{array}{l}\text { 'Furthermore with regards to the fact that one cannot simply forget } \\
\rightarrow \text { and if I have interpreted you correctly, move away from the past, that is } \\
\text { move away from this black and white notion of racism that it is unfair for } \\
\text { people to reconcile and even to not hold grudges against those who once } \\
\text { oppressed the other?' }\end{array}$ \\
\hline
\end{tabular}

A space for challenging one's own reality and that of one's peers: As well as providing a safe space for students to talk about race and racism, an asynchronous online environment also affords an automatic time delay, which may help students reflect more deeply about their own and one another's thoughts, compelling them to generate insightful, contemplative messages (Qui, Hewitt and Brett 2014, 295, 297). Needless to say, the fact that time expands exponentially may, paradoxically, lead to unforeseen problems: if the time lag between responses is too great, students may lose interest in maintaining meaningful dialogue and in some cases, may even drop out of conversational threads entirely (Dringus and Ellis 2010, 347; Gao, Zhang and Franklin 2013, 473). In our own dataset, we noticed that students did not always respond to one another's messages in a timely fashion, and potentially stimulating discussions therefore fell by the wayside. One possible reason for the absence of contributions is the tendency among students to respond to the most recent posts, while ignoring older messages (Gao et al. 2013, 473).

To encourage rigorous debate, we asked students not only to share their views on racism, but also to justify their comments and challenge those of their peers. In this way, our students moved beyond knowledge sharing to generate counter-assertions in the form of reflective contributions. However, these responses (couched as challenges, responses to challenges as 
well as substantive disagreements) made up only 17 per cent of the total number of moves generated, a finding which mirrors that of other researchers who have explored levels of critical engagement in asynchronous settings (Paulus and Phipps 2008; Lang 2010). Learning contributions made up a mere 0.8 per cent of the total number of moves coded, an outcome which Paulus and Phipps (2008, 476-477) speculate could be ascribed to task-type: as mentioned earlier, our main instruction to students hinged on answering specific questions related to an article in Cosmopolitan. These questions stimulated critical reflection and some self-reflection among our students (as demonstrated in the learning moves identified), but it would have been fruitful to encourage more self-reflection by explicitly encouraging students to interrogate their own constructs about race and racism. Students tended to shy away from interrogating their own assumptions about these constructs, commenting either on the content of the article or on the views of their peers. In their study of sensitive multi-cultural topics discussed in online forums, Licona and Guring $(2011,4)$ contend that students must 'take risks with their [...] implicit identities' - those identities that conceal their personal and cultural identities - in order for self-reflection to occur.

Although contentious issues provoke lively debate (Blau and Barak 2012, 20; Chadha and Van Vechten 2013a, 7), recent studies (Chadha and Van Vechten 2013b; Scheid and Vasko 2014) suggest that students are averse to voicing their opinions, often because they are afraid of being judged by their peers. It also appears to be a myth that explicitly instructing students to ask probing questions at the beginning of a given course routinely results in deeper levels of critical engagement (Darabi, Arrastia, Nelson, Cornile and Liang 2011, 216).

When setting up subsequent online discussions, we intend avoiding the practice of leaving students to direct their discussions without the presence of the instructor/facilitator. We noted earlier that some studies have found that intervention or over-intervention by the facilitator may inhibit student-student interaction (An et al. 2009, 758; Murphy and Fortner 2014, 345). However, it has also been found that students who are engaged in difficult dialogues find a passive role on the part of the facilitator unhelpful (Sue, Lin, Torino, Capodilupo and Rivera 2009, 188). Murphy and Fortner $(2014,340)$ recommend that instructors engage in 'a modest level of [modelling]' to foster stimulating dialogue. Another strategy is to monitor students' posts with a view to determining if they are generating true threaded discussions. A fully threaded discussion is one in which students have the freedom to author a topic thread they and their co-participants can then elaborate on (Rhoades and Rhoades 2013, 68). Although we constructed a space in which students could initiate topics, these topics were not explored at all in a few cases, resulting in non-threads. By pre-empting unproductive threads, we could have 
encouraged students to support their views in substantive ways. It goes without saying that the nature of an instructor's encouragement needs to be carefully considered too: simply summarising a student's ideas or posting one-word remarks such as 'Interesting point' effectively puts an end to dialogue (Monroe 2003, 32). Rather, instructors should facilitate fully threaded discussions through questions that seek clarification, those that constructively interrogate ideas (Lim, Cheung and Hew 2011, 63), novel perspectives on ideas introduced, or comments aimed at uncovering implicit assumptions (Monroe 2003, 32).

Still on the topic of threads, it is best to avoid allowing all students to post initial messages, a practice we did not require but which we did not discourage. Monroe (2003, 32) quite rightly points out that this practice not only results in redundancy, but also disperses the various conversational threads, resulting in superficial exchanges. Constructing a space in which students did not communicate in small groups but could respond to threads of their choice diluted potentially meaningful dialogue even further. Being placed in smaller groups would have allowed students to produce more in-depth responses to one or two themes/ideas (Schellens and Valcke 2006, 349). In her study of a multi-national online classroom, Dzubinski $(2014,6)$ observes that students reported feeling overwhelmed when confronted by too many posts and threads (cf. Gao et al. 2013, 473; Kim and Shaw 2014, 100); eight or more posts were considered cognitively difficult to process.

A space for managing micro-aggressions: One of the risks inherent in leaving students to their own devices in the context of a difficult dialogue is that micro-aggressions among them may go unmanaged. We found several as already indicated. Micro-aggressions, which are more often than not expressed as subtle rather than blatant insults, assaults and invalidations (Boysen 2012, 123), are sometimes ignored by instructors, particularly when they are white (DiAngelo 2012, 1). However, a study by Boysen (2012) signals that students believe it is essential that instructors address covert or overt forms of bias. As teachers of courses with a focus on social justice issues, we need multi-cultural knowledge and awareness to both perceive and address bias, whether it is subtle or blatant. Boysen (2012, 127-128) suggests that initiating a discussion when a micro-aggression has occurred is an effective response, since 'it allows the ambiguous nature of the [micro-aggression] to be elucidated for those who might not be aware that bias has occurred'.

A space for engagement, not participation: The discussion instructions our students were provided with were aligned with the learning objectives of the course, and also emanated from our conceptual framework outlining what a productive online discussion entails. Without explicit guidelines for peer interaction, students have a tendency to post monologues, thus 
functioning in a spatial vacuum (cf. Zydney, deNoyelles and Seo 2012, 78). In addition to composing detailed instructions about the kinds of interactional patterns to be generated, we also designed the initial prompt around several pertinent questions, not only to direct the discussion, but also to encourage students to co-construct knowledge. Although we were disappointed that students in the long run did not produce as many reflective and learning contributions as we would have liked, they nevertheless generated many factual contributions. Several also challenged one another's views, and even if students did not offer many rebuttals, they agreed or disagreed with one another, and asked a number of reflective questions rather than simply information-driven ones.

Re-visiting our instructional design and data, however, we need to re-consider our decision to award students an attendance or participation mark only. This category of performance criteria, which is certainly one of many factors that helps shape engagement in an online forum (Jackson 2010, 455) nevertheless constitutes 'non-achievement' criteria (Sadler 2009, 813). We do not argue that a grade for participation should be discarded altogether, but that it should not be the only means of assessing students' posts. Students may be tempted to post a few superficial comments to obtain a mark. If students are aware from the outset that their contributions will be evaluated in terms of quality and not quantity, we believe they will be less inclined to dash off non-substantive messages.

A space for student-content engagement: A naïve assumption on our part was that students would not only draw on their personal experiences, but that they would also engage with the course content provided - that they would make use of theories, quotations, and lecture notes, amongst other things, to expand on claims, answer questions, disagree with statements made or offer challenges. As indicated, very few responses included reference to content. With hindsight, we now realise that in order to facilitate student-content interaction, we need to go beyond simply asking students to generate substantive responses. When asked to justify their comments, it appears that students have a tendency to do so by elaborating on personal experiences and general knowledge only. Such communication should not be inhibited of course: 'students derive an enormous amount of motivation and enjoyment' (Mokoena 2013, 101) from sharing personal experiences. What is more, when it comes to discussing social issues, students should share real-life experiences. However, students do need to process course content too. Ertmer et al. (2011, 173-174) recommend that instructors not only modify their question prompts in such a way that they directly instruct students to engage with course content, but that they also post additional guided questions in the event that they notice that students are not validating their responses through reference to course content. 


\section{CONCLUSION}

We set out to determine if our students' discussions of race and racism in an online forum would reflect higher levels of critical engagement. We found that while students' posts exhibited many instances of knowledge sharing, neither knowledge-construction nor knowledge-creation discourses were as prevalent as we expected they would be. This is problematic, since '[u]nderstanding issues related to social justice [...] involves complex thinking about highly personal experiences' (Guthrie and McCracken 2010, 88). We realise that productive online discussion in the context of a difficult dialogue hinges on task design, which must take social, teaching, and cognitive elements into account: without social presence, interaction and social cohesion cannot be established. A lack of teaching presence makes it difficult for students to achieve higher-order thinking and without cognitive presence, students cannot co-construct meaning and critically reflect on understanding (Putman, Ford and Tancock 2012, 152).

Our contribution to existing knowledge about facilitating critical enquiry in an online environment is a more comprehensive coding scheme which describes what meaningful online discussion should look like. It is an amalgamation and extension of influential models of online discussion and may usefully be employed as an assessment rubric by instructors working in online settings. The coding scheme also does not disregard the importance of participatory contributions which may help shape collaborative enquiry. Since we are working in the context of difficult dialogues, our research in the future will focus on refining the coding scheme so that it can assist us in perceiving micro-aggressions and emotional responses, unavoidable elements when it comes to the discussion of sensitive social matters.

We have highlighted some misguided assumptions about what we believed our task design would elicit so that other instructors can learn from our mistakes. Although we were focused on critical engagement, we became increasingly aware of students' emotional responses to race and racism as we immersed ourselves in the data. We cannot ignore the fact that while we want our students to feel safe when they speak about controversial topics, they need to enter a brave space too: 'our approach to initiating social justice dialogues should not be to convince participants that we can remove risk from the equation, for this is simply impossible' (Arao and Clemens 2013, 136).

\section{REFERENCES}

An, H., S. Shin and K. Lim. 2009. The effects of different instructor facilitation approaches on students' interactions during asynchronous online discussions. Computers and Education 53(3): 749-760.

Annand, D. 2011. Social presence within the community of inquiry framework. The International 
Review of Research in Open and Distributed Learning 12(5): 40-56.

Arend, B. 2009. Encouraging critical thinking in online threaded discussions. Journal of Educators Online 6(1): 1-23.

Arao, B. and K. Clemens. 2013. From safe spaces to brave spaces: A new way to frame dialogue around diversity and social justice. In The art of effective facilitation, ed. L. M. Landreman, 135-150. Sterling, VA: Stylus Publishing, LLC.

Attwood, F. 2005. 'Tits and ass and porn and fighting': Male heterosexuality in magazines for men. International Journal of Cultural Studies 8(1): 83-100.

Bender, T. 2003. Discussion-based online teaching to enhance student learning: Theory, practice, and assessment. Sterling, VA: Stylus.

Blau, I. and A. Barak. 2012. How do personality, synchronous media, and discussion topic affect participation? Educational Technology \& Society 15(2): 12-24.

Booth, S. and M. Hultén. 2003. Opening dimensions of variation: An empirical study of learning in a web-based discussion. Instructional Science 31(1-2): 65-86.

Boyd, M. 2012. From the comfort of your office: Facilitating learner-centered continuing education in the online environment. Cataloging \& Classification Quarterly 50(2-3): 189-203.

Boysen, G. A. 2012. Teacher and student perceptions of micro-aggressions in college classrooms. College Teaching 60(3): 122-129.

Buchanan, J., S. T. Wilson and N. Gopal. 2008. A cross cultural virtual learning environment for students to explore the issue of racism: A case study involving the UK, USA and SA. Social Work Education 27(6): 671-682.

Chadha, A. and R. B. Van Vechten. 2013a. Learning from each other: Dialogic argumentation in an online academic environment. APSA 2013 Annual Meeting Paper: 1-31.

Chadha, A. and R. B. Van Vechten. 2013b. How students talk to each other: Findings from an academic social networking project. In Teaching civic engagement: From student to active citizen, ed. A. R. M. McCartney, E. A. Bennion and D. Simpson, 167-188. Washington, DC: American Political Science Association.

Chang, M. M., M. C. Lin and M. J. Tsai. 2012. A study of enhanced structural web-based discussion in a foreign language learning class. Computers and Education 61: 232-241.

Cleveland-Innes, M. and P. Campbell. 2012. Emotional presence, learning, and the online learning environment. The International Review of Research in Open and Distributed Learning 13(14): 269-292.

Cui, G., B. Lockee and C. Meng. 2013. Building modern online social presence: A review of social presence theory and its instructional design implications for future trends. Education and information technologies 18(4): 661-685.

Cui, A., M. Zhang, Y. Liu and S. Ma. 2011. Emotion tokens: Bridging the gap among multilingual Twitter sentiment analysis. In Information retrieval technology, ed. M. Salem, K. Shaalan, F. Oroumchian, A. Shakery and H. Khelalfa, 238-249. Berlin: Springer.

Darabi, A., M. C. Arrastia, D. W. Nelson, T. Cornille and X. Liang. 2011. Cognitive presence in asynchronous online learning: A comparison of four discussion strategies. Journal of Computer Assisted Learning 27(3): 216-227.

Dare, A. 2011. (Dis)Embodied difference in the online class: Vulnerability, visibility, and social justice. MERLOT Journal of Online Learning and Teaching 7(2): 279-287.

DeCuir, J. and A. Dixon. 2004. So when it comes out, they aren't that surprised that it is there: Using critical race theory as a tool of analysis of race and racism in education. Educational Researcher 33(5): 26-31.

del-Teso-Craviotto, M. 2006. Words that matter: Lexical choice and gender ideologies in women's magazines. Journal of Pragmatics 38(11): 2003-2021. 
Dessel, A. B. 2010. Effects of intergroup dialogue: Public school teachers and sexual orientation prejudice. Small Group Research 41(5): 556-592.

De Wever, B., T. Schellens, M. Valcke and H. Van Keer. 2006. Content analysis schemes to analyze transcripts of online asynchronous discussion groups: A review. Computers \& Education 46(1): 6-28.

DiAngelo, R. 2012. Nothing to add: The role of white silence in racial discussions. Journal of Understanding and Dismantling Privilege 2(1): 1-17.

Dringus, L. P. and T. Ellis. 2010. Temporal transitions in participation flow in an asynchronous discussion forum. Computers \& Education 54(2): 340-349.

Dzubinski, L. 2014. Teaching presence: Co-creating a multi-national learning community in an asynchronous classroom. Online Learning: Official Journal of the Online Learning Consortium 18(2): 1-16.

Ertmer, P. A., A. Sadaf and D. Ertmer. 2011. Student-content interactions in online courses: The role of question prompts in facilitating higher-level engagement with course content. Journal of Computing in Higher Education 23: 157-186.

Gao, F., C. X. Wang and Y. Sun 2009. A new model of productive online discussion and its implications for research and instruction. Journal of Educational Technology Development and Exchange 21(1): 65-78.

Gao, F., T. Zhang and T. Franklin. 2013. Designing asynchronous online discussion environments: Recent progress and possible future directions. British Journal of Educational Technology 44(3): 469-483.

Garrison, D. R., T. Anderson and W. Archer W. 2001. Critical thinking, cognitive presence, and computer conferencing in distance education. American Journal of Distance Education 15(1): 723.

Gayle, M. B., D. Cortez and R. W. Preiss. 2013. Safe spaces, difficult dialogues, and critical thinking. International Journal for the Scholarship of Teaching and Learning 72(2): 5-10.

Geertz, C. 1973. Thick description: Toward an interpretive theory of culture. In The interpretation of cultures, ed. C. Geertz, 3-30. New York: Basic Books.

Giesbers, B., B. Rienties, D. T. Tempelaar and W. Gijselaers. 2014. Why increased social presence through web videoconferencing does not automatically lead to improved learning. E-Learning and Digital Media 11(1): 31-45.

Gilbert, L. S. 2002. Going the distance: 'Closeness' in qualitative data analysis software. International Journal of Social Research Methodology 5(3): 215-228.

Gill, A. J., D. Gergle, R. M. French and J. Oberlander, J. 2008. Emotion rating from short blog texts. In Proceedings of the ACM Conference on Human Factors in Computing Systems, 1121-1124. New York, NY: Association for Computing Machinery.

Gunawardena, C. N., C. A. Lowe and T. Anderson. 1997. Analysis of a global online debate and the development of an interaction analysis model for examining social construction of knowledge in computer conferencing. Journal of Educational Computing Research 17(4): 397-431.

Guthrie, K. L. and H. McCracken. 2010. Teaching and learning social justice through online servicelearning courses. The International Review of Research in Open and Distributed Learning 11(3): $1-8$.

Hadjionnou, X. 2007. Bringing the background to the foreground: What do classroom environments that support authentic discussions look like? American Educational Research Journal 44(2): 370-399.

Hancock, J. T., C. Landrigan and C. Silver. 2007. Expressing emotion in text-based communication. In Proceedings of the SIGCHI conference on Human Factors in Computing Systems, ed. M. B. Rosson and D. Gilmore, 929-932. New York, NY: Association for Computing Machinery.

Hancock, J. T., K. Gee, K. Ciaccio and J. M. H. Lin. 2008. In Proceedings of the 2008 ACM Conference on Computer Supported Work, ed. B. Begole and D. W. McDonald, 295-298. New York, NY: 
Association for Computing Machinery.

Herring, S. C. 2010. Web content analysis: Expanding the paradigm. In International handbook of Internet research, ed. J. Hunsinger, L. Klastrup and M. Allen, 233-249. Dordrecht: Springer.

Holley, L. C. and S. Steiner. 2005. Safe space: Student perspectives on classroom environment. Journal of Social Work Education 41(1): 49-64.

Jackson, K. 2010. What value assessment rubrics in shaping students' engagement in asynchronous online discussions? In Curriculum, technology \& transformation for an unknown future, ed. C. H. Steel, M. J. Keppel, P. Gerbic and S. Housego, 454-458. Brisbane, Australia: The University of Queensland.

Journell, W. 2008. Facilitating historical discussions using asynchronous communication: The role of the teacher. Theory and Research in Social Education 36(4): 317-55.

Ke, F. 2010. Examining online teaching, cognitive, and social presence for adult students. Computers \& Education 55: 808-820.

Khuri, M. L. 2004. Working with emotion in educational intergroup dialogue. International Journal of Intercultural Relations 28(6): 595-612.

Kim, J. and E. Shaw. 2014. Scaffolding student online discussions using past discussions: PedaBot studies. Artificial Intelligence Review 41(1): 97-112.

Lang, Q. C. 2010. Analysing high school students' participation and interaction in an asynchronous online project-based learning environment. Australasian Journal of Educational Technology 26(3): 327-340.

Lee, S. M. 2014. The relationships between higher order thinking skills, cognitive density, and social presence in online learning. Internet and Higher Education 21: 41-52.

Leonardo, Z. and R. K. Porter. 2010. Pedagogy of fear: Toward a Fanonian theory of 'safety' in race dialogue. Race Ethnicity and Education 13(2): 139-157.

Licona, M. M. and B. Gurung. 2011. Asynchronous discussions in online multicultural education: Praxis retained. Multicultural Education 19: 2-8.

Lim, S. C. R, W. S. Cheung and K. F. Hew. 2011. Critical thinking in asynchronous online discussion: An investigation of student facilitation techniques. New Horizons in Education 59(1): 52-65.

Lin, H. S., Z. R. and F. Lawrenz. 2012. Promoting and scaffolding argumentation through reflective asynchronous discussions. Computers \& Education 59(2): 378-384.

Lucas, M., C. Gunawardena and A. Moreira 2014. Assessing social construction of knowledge online: A critique of the interaction analysis model. Computers in Human Behavior 30: 574-582.

Marchand, G. C. and A. P. Gutierrez. 2012. The role of emotion in the learning process: Comparisons between online and face-to-face learning settings. The Internet and Higher Education 15(3): 150160.

Martin, K. H. 2013. Leveraging disinhibition to increase student authority in asynchronous online discussion. Online Learning: Official Journal of the Online Learning Consortium 17(3): 1-15.

Mayo, C, 2010. Incongruity and provisional safety: Thinking through humor. Studies in Philosophy and Education 29(6): 509-521.

Mega, C., L. Ronconi and R. De Beni 2014. What makes a good student? How emotions, self-regulated learning, and motivation contribute to academic achievement. Journal of Educational Psychology 106(1): 121-131.

Mokoena, S. 2013. Engagement with and participation in online discussion forums. The Turkish Online Journal of Educational Technology 12(2): 97-105.

Monroe, B. 2003. Fostering critical engagement in online discussions: The Washington State University study. Washington Centre for Improving the Quality of Undergraduate Education Newsletter: 3133.

Murphy, C. A. and R. A. Fortner. 2014. Impact of instructor intervention on the quality and frequency 
of student discussion posts in a blended classroom. MERLOT Journal of Online Learning and Teaching 10(3): 337-350.

Nandi, D., M. Hamilton, S. Chang and S. Balbo, S. 2012. Evaluating quality in online asynchronous interactions between students and discussion facilitators. Australasian Journal of Educational Technology 28(4): 684-702.

Paulus, T. M. and G. Phipps. 2008. Approaches to case analyses in synchronous and asynchronous environments. Journal of Computer-Mediated Communication 13(2): 459-484.

Petty, N. J., O. P. Thomson and G. Stew. 2012. Ready for a paradigm shift? Part 2: Introducing qualitative research methodologies and methods. Manual Therapy 17(5): 378-384.

Piaget, J. 1977. The development of thought: Equilibrium of cognitive structures. New York, NY: Viking.

Pierce, C. 1970. Offensive mechanisms. In The black seventies, ed. F. Barbour, 265-282. Boston, MA: Sargent.

Putman, S. M., K. Ford and S. Tancock. 2012. Redefining online discussions: Using participant stances to promote collaboration and cognitive engagement. International Journal of Teaching and Learning in Higher Education 24(2): 151-167.

Quan, C. and F. Ren. 2010. Sentence emotion analysis and recognition based on emotion words using Ren-CECps. International Journal of Advanced Intelligence 2(1): 105-117.

Quaye, S. J. 2012. Think before you teach: Preparing for dialogues about racial realities. Journal of College Student Development 53(4): 542-562.

Qui, M., J. Hewitt and C. Brett. 2014. Influence of group configuration on online discourse writing. Computers and Education 71: 289-302.

Redmond, P. 2011. From face-to-face teaching to online teaching: Pedagogical transitions. In Proceedings ASCILITE 2011: 28th Annual Conference of the Australasian Society for Computers in Learning in Tertiary Education: Changing Demands, Changing Directions, ed. G. Williams, P. Statham, N. Brown and B. Cleland, 1050-1060. Hobart, Australia: Australasian Society for Computers in Learning in Tertiary Education.

Reidel, M. and C. Salinas. 2011. The role of emotion in democratic dialogue: A self study. Social Studies Research \& Practice 6(1): 2-20.

Remesal, A. and R. Colomina. 2013. Social presence and online collaborative small group work: A socioconstructivist account. Computers \& Education 60(1): 357-367).

Rhoades, J. and R. Rhoades. 2013. The complexity of online discussion. MERLOT Journal of Online Learning and Teaching 9(1): 68-79.

Rientes, B. and B. A. Rivers. 2014. Measuring and understanding learner emotions: Evidence and prospects. Learning Analytics Review 1: 1-28. http://www.laceproject.eu/learning-analyticsreview/measuring-and-understanding-learner-emotions/ (accessed: 29 March 2015).

Rourke, L. and H. Kanuka. 2009. Learning in communities of inquiry: A review of the literature. Journal of Distance Education 23(1): 19-48.

Sadler, D. R. 2009. Grade integrity and the representation of academic achievement. Studies in Higher Education 34(7): 807-826.

Schellens, T. and M. Valcke. 2006. Fostering knowledge construction in university students through asynchronous discussion groups. Computers \& Education 46(4): 349-370.

Shea, P., S. Hayes, J. Vickers, M. Gozza-Cohen, S. Uzuner, R. Mehta, A. Valchova and P. Rangan. 2010. A reexamination of the community of inquiry framework: Social network and content analysis. The Internet and Higher Education 13(1-2): 10-21.

Shen, L. and I. L. Chen. 2014. Social presence in online dissertation classes. In Educational, psychological, and behavioral considerations in niche online communities, ed. V. Venkatesh, J. Wallin, J. C. Castro and J. E. Lewis, 175-191. USA: IGI Global. 
Simpson, P. and A. Mayr. 2010. Language and power: A resource book for students. USA and Canada: Routledge.

Smith, R. and J. Flaherty. 2013. The importance of social presence in an online MBA program: A preliminary investigation. Teaching \& Learning Innovations 16: 1-19.

Soudien, C. 2010. Grasping the nettle? South African higher education and its transformative imperatives. South African Journal of Higher Education 24(6): 881-896.

Sue, D. W., C. M. Capodilupo, G. C. Torino, J. M. Bucceri, A. M. B. Holder, K. L. Nadal and M. Esquilin, 2007. Racial microaggressions in everyday life: Implications for clinical practice. American Psychologist 62(4): 271-286.

Sue, D. W. 2010. Microagressions in everyday life: race, gender, and sexual orientation. Hoboken, NJ: John Wiley \& Sons.

Thomas, J. 2013. Exploring the use of asynchronous online discussion in health care education: A literature review. Computers \& Education 69: 199-215.

Tracy, S. J. 2010. Qualitative quality: Eight 'big-tent' criteria for excellent qualitative research. Qualitative Inquiry 16(10): 837-851.

Van Aalst, J. 2009. Distinguishing knowledge-sharing, knowledge-construction, and knowledgecreation discourses. International Journal of Computer-Supported Collaborative Learning 4(3): 259-287.

Verwey, C. and M. Quayle. 2012. Whiteness, racism, and Afrikaner identity in post-apartheid South Africa. African Affairs 111(445): 551-575.

Vygotsky, L. S. 1978. Mind in society: The development of higher psychological processes. Cambridge, MA: Harvard University Press.

Weltzer-Ward, L. 2011. Content analysis coding schemes for online asynchronous discussion. CampusWide Information Systems 28(1): 56-74.

Weltzer-Ward, L. 2014. A synthesized coding framework for asynchronous online discussion research. Unpublished doctoral dissertation. Minneapolis, Minnesota: Walden University. http://146.182.60.12/docview/1513556956?accountid=17207 (accessed 24 March 2015).

Williams, L. and M. Lahman. 2011. Online discussion, student engagement, and critical thinking. Journal of Political Science Education 7(2): 143-162.

Xin, C. 2012. A critique of the community of inquiry framework. The Journal of Distance Education/Revue de l'Éducation à Distance 26 (1): 1-12. http://www.jofde.ca/index.php/jde/ issue/view/65 (accessed 24 March 2015).

Yang, D., J. C. Richardson, B. F. French and J. D. Lehman. 2011. The development of a content analysis model for assessing students' cognitive learning in asynchronous online discussions. Educational Technology Research and Development 59: 43-70.

Zingaro, D. and M. Oztok. 2012. Interaction in an asynchronous online course: A synthesis of quantitative predictors. Journal of Asynchronous Learning Networks 16(4): 71-82.

Zydney, J. M., A. deNoyelles and K. Seo. 2012. Creating a community of inquiry in online environments: An exploratory study on the effect of a protocol on interactions within asynchronous discussions. Computers and Education 58(1): 77-87. 